\title{
Syncope in the Elderly
}

\author{
Helen O' Brien and Rose Anne Kenny
}

Department of Medical Gerontology, TCIN, St James's Hospital, Dublin, Ireland

\begin{abstract}
A rapid change in ageing demographic is taking place worldwide such that healthcare professionals are increasingly treating old and very old patients. Syncope in the elderly is a challenging presentation that is under-recognised, particularly in the acute care setting. The reason for this is that presentation in the older person may be atypical: patients are less likely to have a prodrome, may have amnesia for loss of consciousness and events are frequently unwitnessed. The older patient thus may present with a fall rather than transient loss of consciousness. There is an increased susceptibility to syncope with advancing age attributed to age-related physiological impairments in heart rate and blood pressure, and alterations in cerebral blood flow. Multi-morbidity and polypharmacy in these complex patients increases susceptibility to syncope. Cardiac causes and more than one possible cause are also common. Syncope is a major cause of morbidity and mortality and is associated with enormous personal and wider health economic costs. In view of this, prompt assessment and early targeted intervention are recommended. The purpose of this article is to update the reader regarding the presentation and management of syncope in this rapidly changing demographic.
\end{abstract}

\section{Keywords}

Syncope, elderly, older person, review, cardiac syncope, reflex syncope, neurally mediated, vasovagal, carotid sinus syndrome, orthostatic hypotension

Disclosure: The authors have no conflicts of interest to declare.

Received: 27 May 2014 Accepted: 12 June 2014 Citation: European Cardiology Review, 2014;9(1):28-36

Correspondence: Rose Anne Kenny, The Falls and Blackout Unit, St James's Hospital, Dublin 8, Ireland. E: rkenny@tcd.ie

One of the greatest achievements of public health in the twentieth century has been the almost doubling of life expectancy in the Western world. Yet this now ageing population brings new challenges, as the prevalence of little-understood geriatric conditions increases, together with the rising prevalence of age-related disorders, such as syncope.

The definition of syncope, as outlined by the European Society of Cardiology (ESC), is a transient loss of consciousness (T-LOC) due to global cerebral hypoperfusion characterised by rapid onset, short duration and spontaneous complete recovery. ${ }^{1}$ Previous variations in the definition of syncope have led to its prevalence being poorly appreciated. ${ }^{2}$ By distinguishing syncope/T-LOC from other causes of loss of consciousness (for example, epileptic seizure, concussion), the present definition aims to minimise conceptual and diagnostic confusion. ${ }^{1}$

Why is syncope in the elderly important? Presentation in this age group is challenging and often recognition is the first step to optimising management and care of these patients. To start with, syncope in the older patient is under-recognised, particularly in acute care settings because the presentation is frequently atypical.

The older patient is less likely to have a warning or prodrome prior to syncope, commonly has amnesia for loss of consciousness and frequently experiences an unwitnessed event, ${ }^{3}$ thus presenting with a fall rather than T-LOC. ${ }^{4-6}$ These events are typically described as non-accidental (not a trip or slip) or unexplained falls. Therefore, history alone cannot be relied upon when assessing the older patient. Injurious events such as fractures and head injuries, are also more common, further emphasising the importance of thorough early investigation and diagnosis. ${ }^{3}$

There is an increased susceptibility to syncope with advancing age that is attributed to age-related physiological impairments in heart rate (HR), blood pressure (BP), cerebral blood flow and neurohumoral stability. This, combined with multi-morbidity and polypharmacy in these complex patients adds to their vulnerability. ${ }^{7}$ Furthermore, cardiac causes are more common as patients age. ${ }^{8}$ Emerging evidence has proposed consideration of early insertion of patient-activated internal loop recorder (ILR) devices in this age group. ${ }^{9,10}$

In the older patient, syncope is a major cause of morbidity and mortality and is associated with enormous personal and wider health economic costs.? Quality of life studies have consistently shown that functional impairment induced by syncope is similar to that of chronic diseases such as rheumatoid arthritis and epilepsy ${ }^{11-13}$ underscoring the significant morbidity attached to syncope.

The purpose of this review is to highlight the characteristics and epidemiology of syncope in the older person.

\section{Epidemiology}

The Irish Longitudinal Study on Ageing (TILDA [www.tilda.ie]) is a population-based study of adults 50 years and over that incorporated questions on syncope and falls in addition to a broad spectrum of health, social and economic questions. A number of community dwelling adults $(8,163)$, mean age 62, range 50-106 years, were asked 
whether they experienced fainting in their youth, throughout their life or over the past 12 months. A total of $23.6 \%$ had one or more episodes in the previous 12 months of which $4.4 \%$ were syncope and $19.2 \%$ were falls (see Table 1). Although the prevalence of syncope rose with age, the increase in falls was much more remarkable, in particular the increase in non-accidental or unexplained falls was most striking. Unwitnessed syncope most commonly presents as non-accidental or unexplained falls, supporting the rising prevalence of atypical syncope with advancing years.

The General Practitioners' Transition Project in the Netherlands demonstrated that the age distribution of patients presenting to their GP with syncope shows a peak in females at 15 years of age and a second peak in older patients (see Figure 1).14 The Framingham Offspring study similarly demonstrates a bimodal peak of first syncope in mid-teens and over 70 years. ${ }^{15}$

The true prevalence of syncope is underestimated due to the phenomenon of amnesia for T-LOC. Amnesia has been reported in patients with vasovagal syncope (VS) and carotid sinus syndrome (CSS), ${ }^{3,16}$ but is likely to be present in all causes of syncope. The overlap between syncope and falls also leads to under-reporting. ${ }^{6}$

\section{Causes of Syncope in the Elderly}

Reflex syncope and orthostatic hypotension $(\mathrm{OH})$ are the most frequent causes of syncope in all age groups and clinical settings, and responsible for the majority of episodes in younger patients. However, cardiac causes of syncope, structural and arrhythmic, become more common in older patients and are responsible for one-third of syncope in patients attending the Emergency Room and Chest Pain Unit ${ }^{1,7-19}$ (see Table 2, ${ }^{17-19}$ Figure $2^{20}$ and Figure $3 .{ }^{21}$ )

The prevalence of unexplained syncope varies according to diagnostic facilities and age from 9 to $41 \%$ (see Table $2^{1,17-19}$ ). In the older patient, history may be less reliable and multiple causes of syncope may also be present (see Table 3).,18,22-24 Multi-morbidity and polypharmacy are more common in older patients with syncope and can add to the complexity of identifying an attributable cause of events. ${ }^{25}$

\section{Approach to the Older Person Presenting with Syncope}

\section{Classification}

Syncope is classified as reflex/neurally mediated syncope, syncope secondary to $\mathrm{OH}$ and cardiac syncope. 1

\section{Assessment}

\section{Initial Evaluation}

Initial evaluation should establish whether T-LOC occurred, whether aetiology has been identified and whether there is any evidence of a high risk of cardiovascular events or death. ${ }^{1,21}$ The initial evaluation in patients over 50 years includes detailed history, collateral history, driving history, physical examination, 12-lead electrocardiogram (ECG), measure of orthostatic BP, routine blood tests and CSM. Where possible, the history should elicit 'the 3 PS' (provokers, prodrome, posture), as well as circumstances leading to the event, description of the event, duration of the event, details of the recovery phase and a thorough medication history, ${ }^{1}$ coupled with a witness account. History alone cannot be relied upon in the older population as commonly these patients ( $28 \%$ in one study ${ }^{3}$ ) experience amnesia for loss of consciousness. ${ }^{3,18}$ In $50 \%$ of cases of syncope in the older population
Table 1: Prevalence of Syncope and Falls in One Year from The Irish Longitudinal Ageing Study (TILDA) (Personal Communication)

\begin{tabular}{|c|c|c|c|c|}
\hline Previous Year \% & 50-64 years & 65-74 years & $75+$ years & Total \\
\hline Syncope & 4.17 & 4.74 & 4.84 & 4.42 \\
\hline Falls & 17.46 & 19.46 & 24.43 & 19.19 \\
\hline $\begin{array}{l}\text { Non-accidental/ } \\
\text { unexplained falls }\end{array}$ & 7.61 & 9.41 & 11.58 & 8.87 \\
\hline
\end{tabular}

Figure 1: Frequency of Fainting as the Reason for Visits to General Practice in The Netherlands

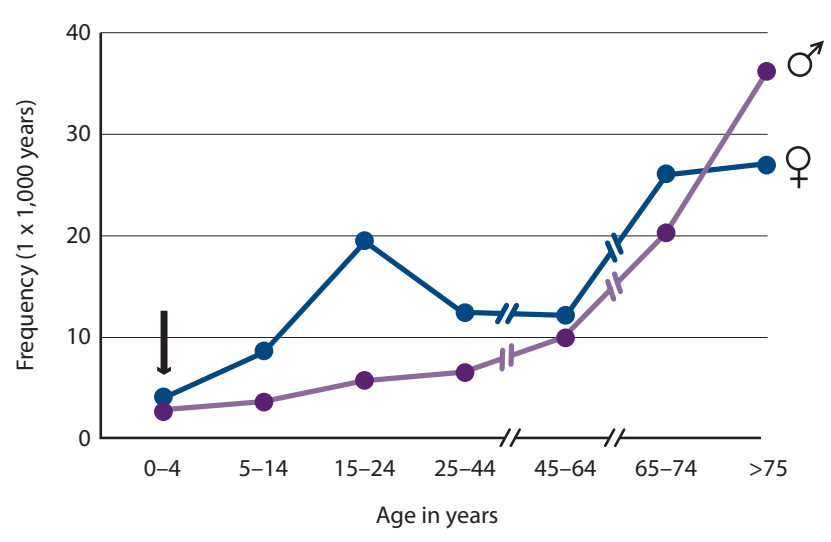

Data are obtained from the general practitioners' transition project. It concerns an analysis of 93,297 patient-years. The arrow around 1 year is to indicate that a small peak occurs between 6-18 months. Permission from The Dutch Journal of Medicine/Nederlands tijdschrift voor geneeskunde. ${ }^{14}$

an accurate collateral history is not available. ${ }^{6}$ The differential diagnosis of syncope most frequently includes epilepsy, strokes and transient ischaemic episodes and falls (see Table 4). ${ }^{1}$ The absence of T-LOC is important in differentiating between syncope and 'drop attacks', which are defined as a loss of postural control when the patient falls without loss of consciousness but with difficulty in resuming the erect position after the event. ${ }^{26}$

If syncope remains undiagnosed, further investigation is necessary, including in head-up tilt (HUT), cardiac investigations and ambulatory BP monitoring. ${ }^{24,27}$ In some studies up to $30 \%$ of older patients with syncope have more than one possible attributable cause, emphasising the necessity for a full comprehensive assessment in the older patient.22,28

\section{1) Reflex Syncope/Neurally Mediated Syncope Vasovagal Syncope}

VS is a neurally mediated reflex in which there is a relatively sudden change in autonomic nervous system activity leading to a fall in BP, HR and cerebral perfusion. ${ }^{29}$ In young patients a diagnosis can usually be made from history alone. This is not always the case with older patients. Although WS is the most common cause of syncope in the older patient, it may not follow the benign course commonly observed in the young..$^{30,31}$ The classic prodrome usually described as pallor, sweating, nausea and dizziness may be shorter in duration or in some instances non-existent or poorly recognised in the older patient.30,32-34 In the older person, WS is more likely due to a dysautonomic response representing an inability of the baroreflex to adapt to physiological challenges, which results in a progressive fall in $\mathrm{HR} \pm \mathrm{BP}$ before the onset of symptoms..$^{35} \mathrm{VS}$ has multiple triggers including a warm environment, prolonged standing, dehydration especially in those on diuretics or anti-hypertensive and vasodilator medications. ${ }^{34}$ 
Table 2: Frequency of the Causes of Syncope According to Age 1,17-19 $^{19}$

\begin{tabular}{|c|c|c|c|c|c|c|c|}
\hline $\begin{array}{l}\text { Age Group } \\
\text { (Years) }\end{array}$ & Source & $\begin{array}{l}\text { Reflex } \\
\%\end{array}$ & $\begin{array}{l}\text { Orthostatic } \\
\text { Hypotension } \\
\%\end{array}$ & $\begin{array}{l}\text { Cardiovascular } \\
\%\end{array}$ & $\begin{array}{l}\text { Non-syncopal } \\
\%\end{array}$ & $\begin{array}{l}\text { Unexplained } \\
\text { Cause } \\
\%\end{array}$ & Setting \\
\hline$<40$ & $\dagger$ & 51 & 2.5 & 1.1 & 18 & 27 & $\mathrm{ED}$ and $\mathrm{CPU}$ \\
\hline $40-60$ & $\dagger$ & 37 & 6 & 3 & 19 & 34 & $\mathrm{ED}$ and $\mathrm{CPU}$ \\
\hline$<65$ & $\neq$ & 68.5 & 0.5 & 12 & & 19 & $\mathrm{CD}$ \\
\hline \multirow[t]{2}{*}{$60 / 65$} & $\ddagger$ & 52 & 3 & 34 & & 11 & $C D$ \\
\hline & $\dagger$ & 25 & 8.5 & 13 & 12.5 & 41 & $\mathrm{ED}$ and $\mathrm{CPU}$ \\
\hline$>75$ & $\S$ & 36 & 30 & 16 & & 9 & GD \\
\hline
\end{tabular}

$C D=$ cardiology department; $C P U=$ chest pain unit; $E D=$ emergency department; GD = geriatric department; $+=$ Olde Nordkamp; $\neq=$ Del Rosso; $\S=$ Ungar. With permission from Oxford University Press (UK) (C) European Society of Cardiology (www.escardio.org/guidelines).

Figure 2: Prevalence of Cardiovascular Disease in Adults $\geq 20$ Years of Age by Age and Sex

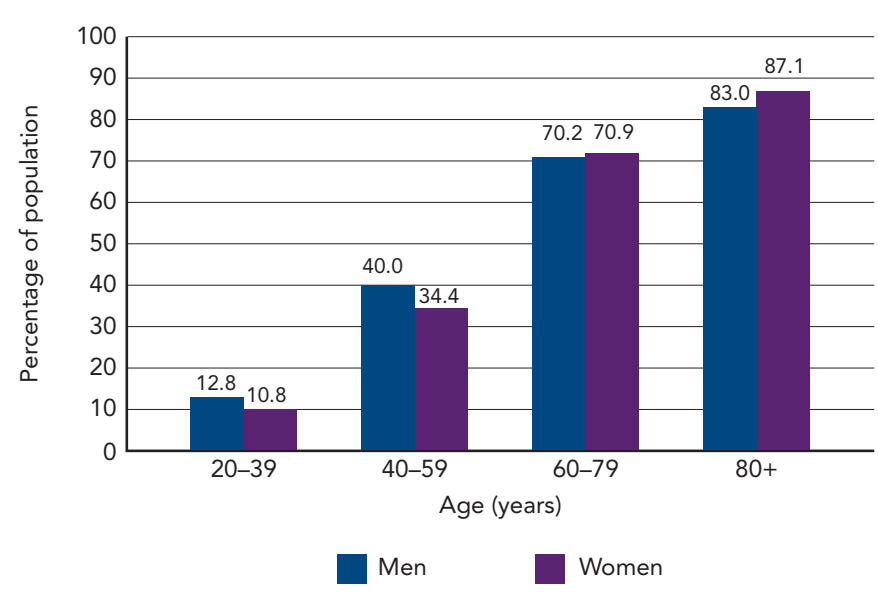

(National Health and Nutrition Examination Survey: 2007-2010). Source: National Center for Health Statistics and National Heart, Lung, and Blood Institute. These data include coronary heart disease, heart failure, stroke, and hypertension. With permission from wolters Kluwer Health. ${ }^{20}$

Figure 3: Causes of Syncope by Age ${ }^{21}$

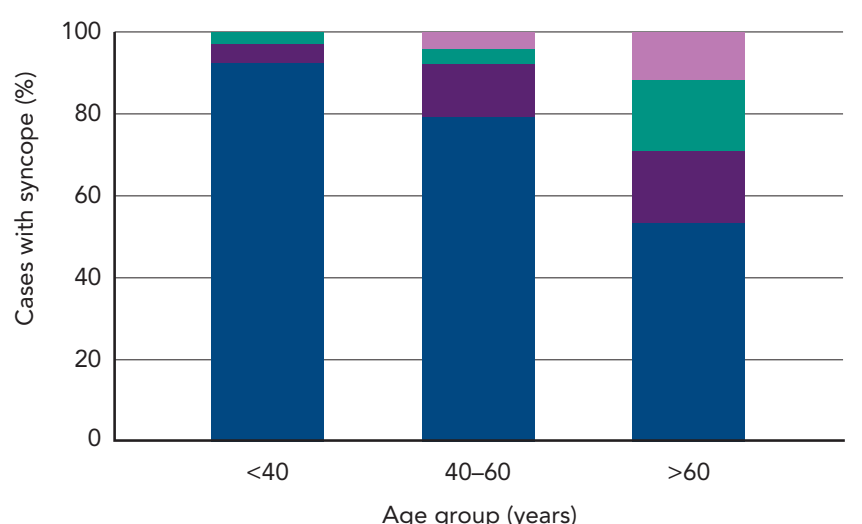

Neurally mediated syncope

Orthostatic hypotension

With permission from BMJ Publishing Group $L t d{ }^{2}$

\section{Investigation}

HUT testing is well tolerated in the older patient ${ }^{34}$ and is indicated in syncope of unknown origin, ${ }^{36}$ when history is atypical, driving is a concern, or serious injury sustained, ${ }^{37}$ and as outlined in the ESC guidelines. ${ }^{1}$ Even the older, frailer patient with cognitive impairment tolerates HUT, ${ }^{38}$ including both passive and GTN-provoked HUT.39,40
The HUT is positive when there is induction of either reflex hypotension/bradycardia or delayed $\mathrm{OH}$ associated with syncope or pre-syncope ${ }^{1}$ with symptom reproduction. In unexplained falls due to reflex syncope, patients may deny witnessed loss of conscioussness induced by HUT. This was the case in $42 \%$ of older patients in one study. ${ }^{3}$ Responses are vasodepressor (hypotension), cardioinhibitory (bradycardia) or mixed. ${ }^{41}$ An exception to the classification is chronotropic incompetence, where the patient has no compensatory rise in HR on HUT. ${ }^{24}$

If HUT results in a cardio-inhibitory response and syncope, capture of a real-time event with early insertion of an ILR9 should be sought. ${ }^{42}$ It is also important to remember that HUT does not always replicate real-time syncopal episodes as has been demonstrated in ILR analysis in patients with VVS. ${ }^{43}$

\section{Implantable Loop Recorder -}

\section{Use in Reflex Syncope}

The International Study on Syncope of Unknown Etiology (ISSUE-2) ${ }^{44}$ trial provided evidence that early ILR insertion to capture syncope in real-time in those with suspected reflex syncope, ensured safe and effective directed therapy in patients experiencing frequent syncope. $^{44}$ The mean age of trial participants was $66 \pm 14$ years. Other characteristics of participants were syncope beginning in middle or older age, frequent injury and short prodrome. The study demonstrated a reduction in recurrent syncope rates following ILR-guided therapy ie. pacemaker insertion, following asystole or bradyarrhythmia. ${ }^{44}$ Fifty per cent of those with recurrent unexplained syncope had asystole during symptoms. ${ }^{44}$

In the ISSUE-3 trial, patients who were ILR positive (documented asystolic episode) but had negative tilt tests, had the best outcomes from cardiac pacing with a $5 \%$ recurrence of syncope at 2 years. ${ }^{45}$ However, $25 \%$ of those who were ILR positive and actively paced had a recurrence of syncope at 2 years, when those with positive and negative tilts tests were included. ${ }^{45,46}$ The study raised questions about the origin of the asystole in the older pacemaker group and whether reflex syncope or age-related conducting tissue disease was responsible. ${ }^{47}$

\section{Management of Vasovagal Syncope}

Cardiac and psychotropic medications can cause hypotension and VVS, therefore initial treatment focuses on modification of culprit medications (up to $40 \%$ ). Management includes education with advice on adequate fluid intake, ${ }^{48}$ physical counter manoeuvres (PCM), compression stockings, tilt training ${ }^{49}$ and feedback to patients of haemodynamic changes correlating with symptoms at the time of HUT. 
Table 3: Numbers and Percentages of Patients with One or More Causes of Syncope

\begin{tabular}{|c|c|c|c|c|c|c|}
\hline \multirow{2}{*}{$\begin{array}{l}\text { Age Group } \\
\text { (Years) }\end{array}$} & \multicolumn{6}{|c|}{ Number of Diagnoses } \\
\hline & 0 & 1 & 2 & 3 & 4 & $0-4$ \\
\hline$<40$ & $49(21.6)$ & $156(68.7)$ & $21(9.2)$ & $1(0.4)$ & $0(0.0)$ & $227(23.0)$ \\
\hline $40-64$ & $62(22.9)$ & $164(60.5)$ & $40(14.8)$ & $5(1.8)$ & $0(0.0)$ & $271(27.5)$ \\
\hline $65-75$ & $44(16.3)$ & $168(62.2)$ & $50(18.5)$ & $8(3.0)$ & $0(0.0)$ & $270(27.4)$ \\
\hline $76-79$ & $19(16.7)$ & $65(57.0)$ & $26(22.8)$ & $4(3.5)$ & $0(0.0)$ & $114(11.6)$ \\
\hline$\geq 80$ & $21(20.0)$ & 57 (54.3) & $25(23.8)$ & $1(1.0)$ & $1(1.0)$ & $105(10.6)$ \\
\hline
\end{tabular}

Causes include cardiac (bradyarrhythmia, supraventricular tachyarrhythmias, ventricular tachyarrhythmias, hypertrophic obstructive cardiomyopathy (Iong QT); non-cardiac (reflex - vasovagal syncope, carotid sinus hypersensitivity, autonomic dysfunction/orthostatic hypotension, cerebrovascular disease); other; unknown, stratified by age group (values are number [percentage] of patients). With permission from Elsevier. ${ }^{22}$

Older patients with VVS are more likely to require cardiac pacing, for example, when spontaneous cardioinhibitory response in the setting of frequent syncope is observed. ${ }^{1}$ Cardiac pacing in VVS is given a class Ila recommendation in international guidelines, in those over 40 years with recurrent reflex syncope and documented spontaneous cardioinhibitory response during monitoring; a Class IIb recommendation for refractory symptoms in the same age group in the presence of a documented cardio-inhibitory response on HUT. ${ }^{1,50}$ The ISSUE-3 trial refines this to include those VVS patients over 40 years, with syncope beginning in middle or older age, ${ }^{51}$ with three or more episodes of syncope in the previous 2 years and spontaneous asystole during monitoring. ${ }^{46,47}$ These patients correspond with those defined by the ESC guidelines as patients with high risk of injury or high frequency of syncope recurrence. ${ }^{1,51}$

\section{Carotid Sinus Hypersensitivity and Carotid \\ Sinus Syndrome}

CSS is exclusively a disorder of ageing and current guidelines advise that carotid sinus massage (CSM) should be performed in patients over 40 years with unexplained syncope. ${ }^{1}$ Careful history taking may reveal triggers such as head turning, tight collars, shaving and vagal stimuli, ${ }^{24}$ although micturition, defaecation and known triggers of VVS can also provoke CSS. Contraindications to CSM include transient ischaemic attack/stroke within 3 months, ${ }^{1}$ recent myocardial ischaemia ${ }^{52}$ or evidence of carotid bruit ${ }^{1}$ unless significant stenosis has been excluded by carotid dopplers. Using the exclusion criteria, the risk of stroke or transient ischaemic attack (TIA) from CSM has been reported as one per 1,000 episodes of massage. ${ }^{27}$

Traditionally, carotid sinus hypersensitivity (CSH) has been defined as a ventricular pause lasting $>3$ seconds and/or a fall in systolic BP of $50 \mathrm{mmHg}$ during CSM without spontaneous syncope. ${ }^{1}$ CSS is diagnosed when the above criteria is associated with spontaneous syncope. ${ }^{1}$ The CSH response is categorised as cardio-inhibitory, vasodepressor or a combination of both. ${ }^{27,45}$ Recently, authors proposed new criteria for exaggerated responses to CSM-asystole $\geq 6$ seconds and a fall in mean arterial $\mathrm{BP} \geq 60 \mathrm{mmHg}$ over 6 seconds $^{53}$ based on data from a population study where the 95th percentile for CSM response was 7.3 seconds of asystole and $77 \mathrm{mmHg}$ drop in systolic BP. ${ }^{8}$ Wieling et al. ${ }^{54}$ observed that there was no LOC before 6 seconds of asystole providing a pathophysiological reason to extend the guidelines. ${ }^{54}$

$\mathrm{CSH}$ may be an epiphenomenon of ageing rather than a disease process given that it is evident in up to $35 \%$ of asymptomatic community-dwelling older people. ${ }^{8}$ Recently, CSH has been associated with cognitive impairment and dementia; however, it is
Table 4: Conditions Incorrectly Diagnosed as Syncope

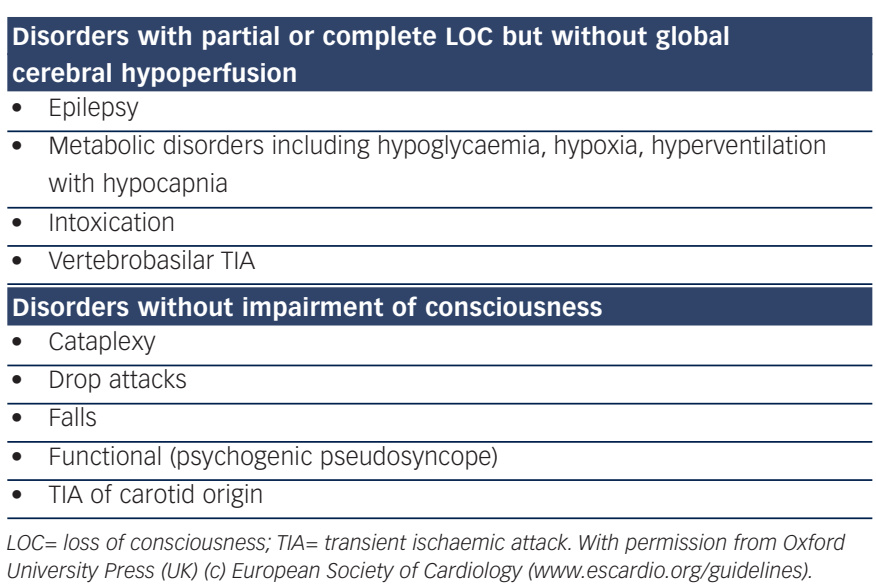

not clear whether it is a risk factor for development of dementia or consequence of neurodegenerative pathology. .5.56 $^{5}$

\section{Investigation}

CSM should be performed in all patients over 40 with syncope of unknown aetiology' and unexplained falls.

\section{Management of Carotid Sinus Hypersensitivity and Carotid Sinus Syndrome}

Although the most common presentation of CSS is syncope, patients

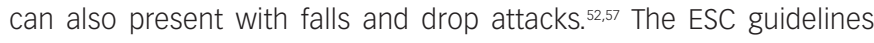
only advise pacing with regard to syncope in CSS. ${ }^{1}$ The American Geriatrics society guidelines on falls prevention in older adults recommend cardiac pacing for $\mathrm{CSH}$ and unexplained/non-accidental falls. ${ }^{58}$ Dual-chamber permanent pacemaker insertion for cardioinhibitory or mixed subtypes of CSS is the treatment of choice. ${ }^{59}$

\section{2) Orthostatic Hypotension}

$\mathrm{OH}$ is defined as a reduction in systolic BP of at least $20 \mathrm{mmHg}$ or in diastolic BP of at least $10 \mathrm{mmHg}$ within 3 minutes of standing..$^{60}$ Orthostatic intolerance (OI) refers to symptoms and signs with upright posture due to circulatory abnormality. ${ }^{1}$ Syndromes of Ol that may cause syncope as per ESC guidelines include: initial $\mathrm{OH}$ where symptoms of lightheadedness/dizziness or visual disturbance are experienced seconds after standing; classic $\mathrm{OH}$ where dizziness, pre-syncope, fatigue, weakness, palpitations, visual and hearing disturbances are experienced; delayed $\mathrm{OH}$ where there is a prolonged prodrome frequently followed by rapid syncope; delayed $\mathrm{OH}$ and reflex syncope where there is a prolonged prodrome always followed by syncope; reflex syncope triggered by standing where there is classic prodrome and triggers always followed by 
Figure 4: Age Dependence of Cardiovascular Responses to Standing Stratified by Gender

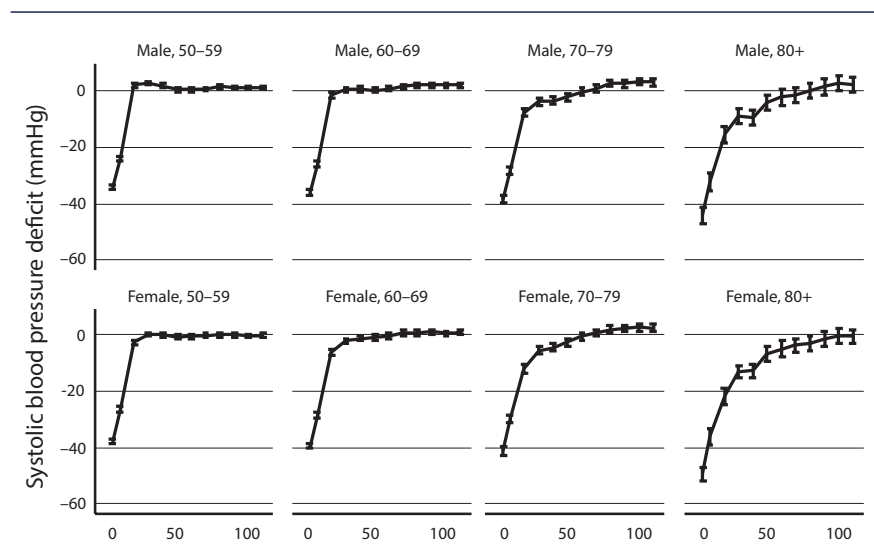

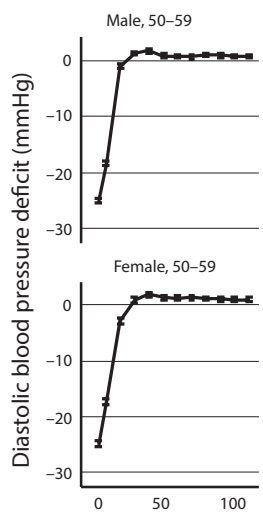
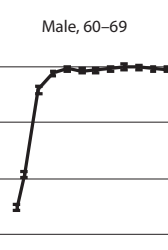

Female, 60-69
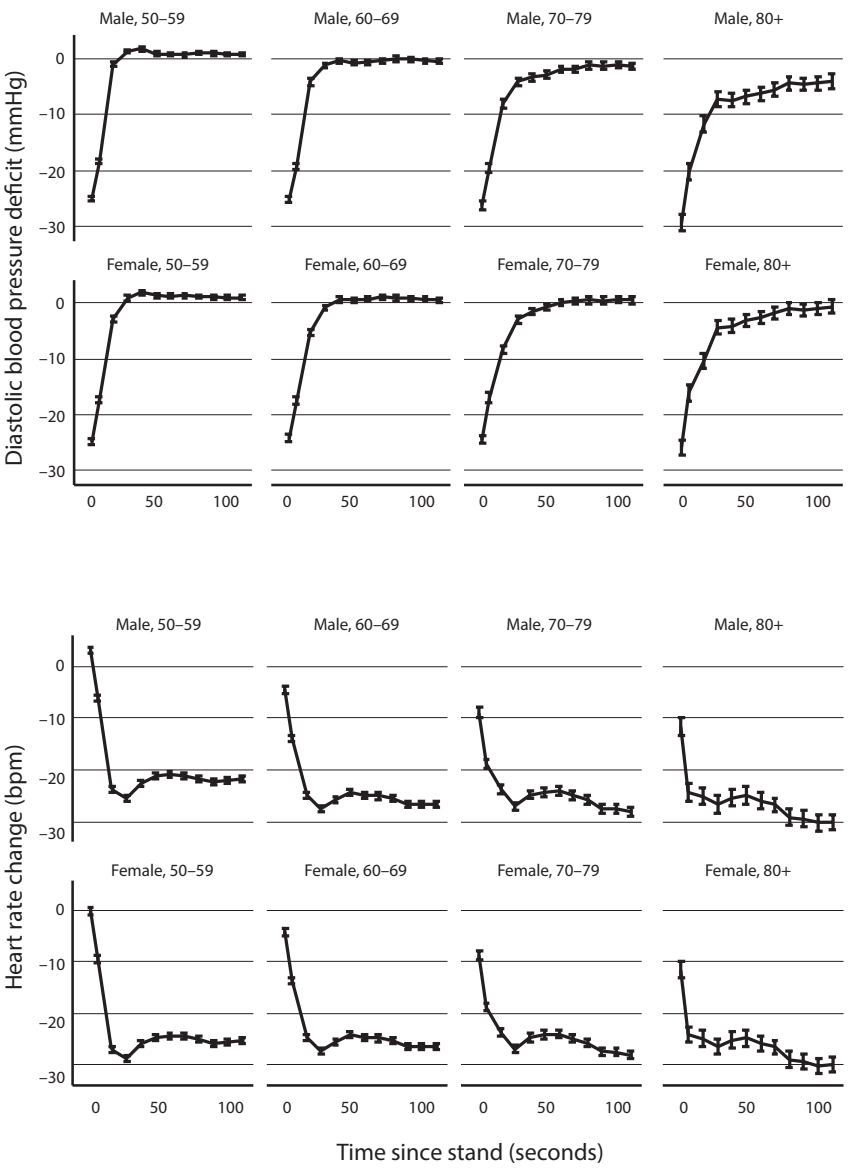

Figure displays mean $\pm 95 \%$ confidence intervals. Finucane et al., Impaired recovery in a large population study: Age related normative changes in phasic orthostatic blood pressure and prevalence of impaired recovery in a large population study: Findings from the Irish Longitudinal Study on Ageing (TILDA) - submitted to Circulation.

syncope and postural orthostatic tachycardia syndrome where there is symptomatic HR increases and instability of BP without syncope. Many older patients with $\mathrm{OH}$ also have postprandial hypotension.

Prevalence of $\mathrm{OH}$ in the older-aged community-dwelling adults is $30 \%$ and increases to more than $50 \%$ in geriatric ward patients ${ }^{62}$ making its diagnosis highly relevant. Causes of $\mathrm{OH}$ include volume depletion or disturbance of the autonomic nervous system resulting in failure in vasoconstrictor compensatory mechanisms induced by upright posture. ${ }^{63}$ The prevalence is higher if phasic BP measures are used. In the TILDA population, $50 \%$ of people over 70 years had persistent $\mathrm{OH}$ up to 40 seconds after standing. Failure of BP to return to baseline values is associated with adverse physical and cognitive outcomes such as syncope, falls, depression and cognitive dysfunction (Finucane, Impaired Orthostatic Blood Pressure Recovery is Independently Associated with an Increased Risk of Falls in Older Community Dwelling Adults; submitted).

The TILDA study has also shown that supine systolic hypertension (SSH) coupled with $\mathrm{OH}$ is a risk factor for cognitive impairment and depression. ${ }^{64}$ There is a striking age gradient in impaired orthostatic BP response as evidenced in Figure 4 (Finucane et al., Age related normative changes in phasic orthostatic blood pressure and prevalence of impaired recovery in a large population study: Findings from the Irish Longitudinal Study on Ageing (TILDA) - submitted to Circulation).

\section{Causes of Orthostatic Hypotension}

The following are the most common causes of $\mathrm{OH}$ in elderly people:

1. medication induced (commonest cause in the older person);

2. primary autonomic failure associated with Parkinson's disease, multisystem atrophy etc.; and

3. secondary autonomic failure for example secondary to diabetic neuropathy or alcoholic autonomic failure and dehydration.

Differential diagnosis must also include anaemia and diagnosis of its underlying cause, Addison's disease or malignancy.

\section{Medication-induced Orthostatic Hypotension}

Syncope due to $\mathrm{OH}$ is linked to the use of vasoactive medications, most commonly diuretics and nitrates. ${ }^{63}$ Many medications cause $\mathrm{OH}$ : cardiovascular medications such as alpha-blockers, diuretics, nitrates, neurological medications, anti-parkinsonian, anti-depressant medications and benzodiazepines. ${ }^{28,60,65}$ Multivariate analysis in one recent study found that predictors of $\mathrm{OH}$ were varicose veins and treatment with alpha-receptor blockers, nitrates or benzodiazepines. ${ }^{28}$

\section{Investigation of Orthostatic Hypotension}

Active standing or passive and unprovoked HUT resulting in symptoms coinciding with a $20 \mathrm{mmHg}$ systolic or diastolic BP drop of $10 \mathrm{mmHg}$ within 3 minutes of orthostatic stress confirms a diagnosis of $\mathrm{OH}^{60}$ $\mathrm{BP}$ and HR usually recover to baseline values within 30 seconds but this reflex increase changes with age and haemodynamic recovery is delayed in elders (see Figure 4, Finucane et al.)

Ambulatory $\mathrm{BP}$ monitoring in $\mathrm{OH}$ patients guides assessment of diurnal variation in $\mathrm{BP}_{1}^{1}$ postprandial hypotension, response to timing of medications and nocturnal supine hypertension.

\section{Management of Orthostatic Hypotension}

Culprit medications should be modified or eliminated and conservative measures adopted prior to consideration of additional pharmacotherapy. ${ }^{66}$ Conservative measures include $\mathrm{PCM}^{67}$ enhanced fluid and salt intake, elevation of the head of bed when sleeping (modifies neuroendocrine control of nocturnal polyuria, redistribution of body fluids and supine hypertension), ${ }^{68,69}$ compression stockings, abdominal binders $s^{70,71}$ and rapid ingestion of cool water for symptoms of OI and post-prandial hypotension. ${ }^{72}$

Medications, such as midodrine (an alpha 1 agonist) ${ }^{73-75}$ and fludrocortisone (a mineralocorticoid that stimulates renal sodium retention and expands intravascular volume), are both well tolerated in the older patient in 
moderate dosages. ${ }^{68}$ Pyridostigmine, octreotide and desmopressin are adjunct therapies but are less well researched in older patients and less well tolerated in our experience.

The combination of $\mathrm{SSH}$ and $\mathrm{OH}$ poses challenging management decisions as treatment of $\mathrm{SSH}$ may worsen symptoms of $\mathrm{OH}^{.7}$ Attention to symptom relief is balanced with treatment of vascular risk associated with SSH. ${ }^{77,78}$ TILDA researchers reported that beta blockers and anti-depressants were risk factors for $\mathrm{OH}$ in people over 50 with $\mathrm{SSH}^{.7}$ Other cardiovascular medications were not associated with $\mathrm{OH}$ in people with $\mathrm{SSH}$.

\section{3) Cardiac Syncope}

One-third of cases of syncope in the older patient are caused by cardiac disorders ${ }^{18}$ (see Figure 3). ${ }^{21}$ There is a higher morbidity and mortality associated with cardiac syncope. ${ }^{15,79}$ Cardiac syncope is characterised by little or no prodrome, occurrence when supine or during exercise and association with palpitations or chest pain.? However, the older patient may not recall these symptoms. Heart disease is an independent predictor of cardiac syncope - sensitivity $95 \%$ and specificity $45 \%$; ${ }^{80}$ the prevalence of cardiac disease, including structural heart disease and arrhythmias, rises dramatically with age as detailed in Figures 2 and 3. ${ }^{20,21,81}$ Cardiac syncope should be considered when the surface ECG is abnormal or left ventricular systolic dysfunction is present. ${ }^{7}$

\section{Investigation}

The gold standard for the diagnosis of cardiac syncope is symptomrhythm correlation i.e. contemporaneous HR and rhythm recording during syncope. Cardiac monitoring may also identify diagnostic abnormalities, such as asystole in excess of 3 seconds and rapid supraventricular (SVT) or ventricular tachycardia (VT). ${ }^{82-84}$ The absence of an arrhythmia during a recorded syncopal event excludes arrhythmia as a cause unless the patient has a dual diagnosis. In patients over 40 years with recurrent unexplained syncope who do not have structural heart disease or abnormal ECG, the attributable cause of syncope is bradycardia in over $50 \% .44,85-87$

\section{Cardiac Monitoring}

Prompt hospital admission or intensive monitoring is recommended when cardiac disease is present in the setting of syncope (see Table 5). ${ }^{1}$ Although telemetry or in-patient monitoring is indicated if the patient is at high risk of a life-threatening arrhythmia as per ECG abnormalities detailed in Table 5, the diagnostic yield from telemetry is low $-16 \%$ in one series. ${ }^{88}$ Holter monitoring is only indicated if a patient is experiencing episodes of sufficient frequency to detect an abnormality up to 72 hours of recording. ${ }^{1}$ Diagnostic yield from Holter monitoring is only $1-2 \%$ in unselected populations. ${ }^{1}$ Incidental arrhythmias are much more common in older persons, for example, atrial fibrillation occurs in one in five men over 80 years. ${ }^{89}$

External loop recorders have a higher diagnostic yield in older patients; however, some older patients may have difficulty operating the devices, ${ }^{90,91}$ therefore automated arrhythmia detection is preferred. ${ }^{92}$ Normal ambulatory ECG (Holter or external loop or otherwise) in the absence of symptoms does not exclude a causal arrhythmia and monitoring for longer intervals is imperative to capture rhythm during symptoms.

Diagnostic rates are much higher in older patients using the ILR, ${ }^{93,94}$ up to $50 \%$ in patients with syncope and unexplained falls., 10,95 Early
Table 5: Risk Stratification - Short-term High-risk Criteria that Require Prompt Hospitalisation or Intensive Evaluation ${ }^{1}$

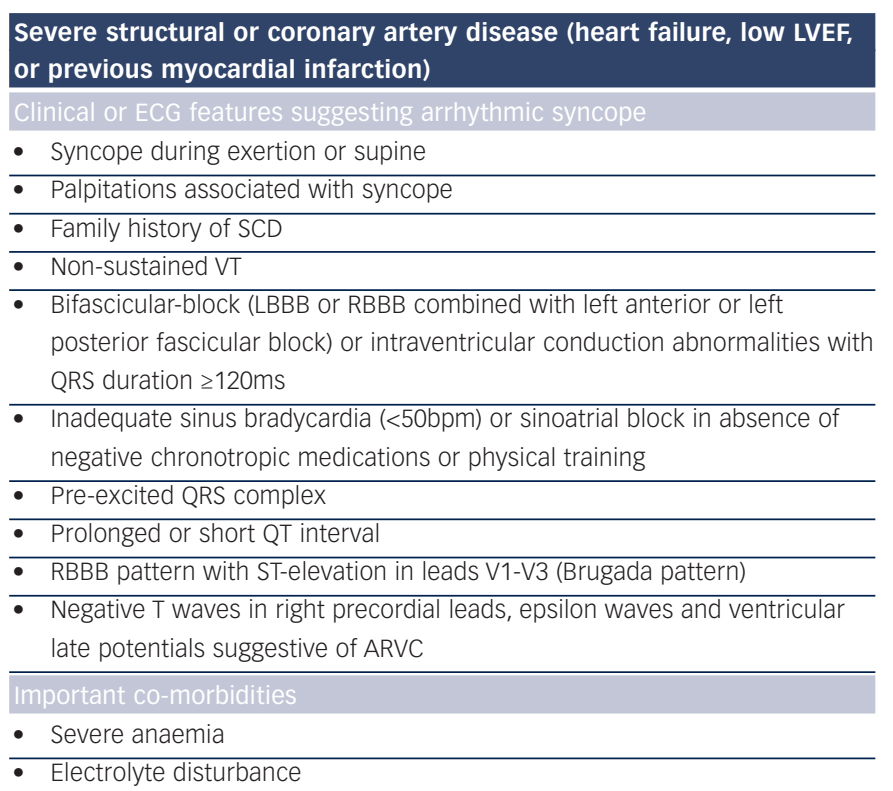

ECG = electrocardiogram; $L / R B B B=$ left/right bundle branch block; $L V E F=$ left ventricular ejection fraction; $S C D=$ sudden cardiac death; $V T=$ ventricular tachycardia. With permission from oxford University Press (UK) (C) European Society of Cardiology (wWw. escardio.org/guidelines).

insertion of ILRS in the older person is important to consider in view of the disproportionately high number of cardiac causes of syncope in this group. ${ }^{9}$ This approach is also more cost-effective. ${ }^{96,97}$ Difficulties with ILRs include inability to activate the device, particularly if patients have cognitive impairment, however, automated recordings and remote monitoring have much improved diagnostic yield. ${ }^{42}$ Magnetic resonance imaging (MRI) brain scans are increasingly used for investigation of other symptoms in elderly persons, therefore, MRI compatible devices should always be used.

\section{Echocardiography}

Echocardiography $(\mathrm{ECHO})$ should be performed in syncope patients in whom a structural abnormality is suspected. The prevalence of structural cardiac abnormalities increases with age..$^{81}$ The test is of most benefit in older patients with aortic stenosis ${ }^{98}$ and to evaluate ejection fraction. Cardiac arrhythmias are evident in up to $50 \%$ of patients with an ejection fraction of less than $40 \% .{ }^{99}$

\section{Ambulatory Blood Pressure Monitoring}

Patterns of BP behaviour including post-prandial hypotension, hypotension after medication ingestion, orthostatic and exerciseinduced hypotension and SSH can be readily identified by this investigation. Modification of timing of meals and medications is guided by BP patterns. .4,100 $^{2}$

\section{Exercise Stress Testing}

Exercise stress testing is indicated to investigate cardiac disease and in patients who present with exercise-induced syncope. ${ }^{1}$ It is not always possible in older patients who may alternatively require angiography to investigate cardiac status.

\section{Electrophysiological Study}

Electrophysiological study is indicated in the older non-frail patient with syncope when a cardiac arrhythmia is suspected..$^{24}$ Diagnosis 
Table 6: Recommendations: Treatment of Syncope Due to Cardiac Arrhythmias ${ }^{1}$

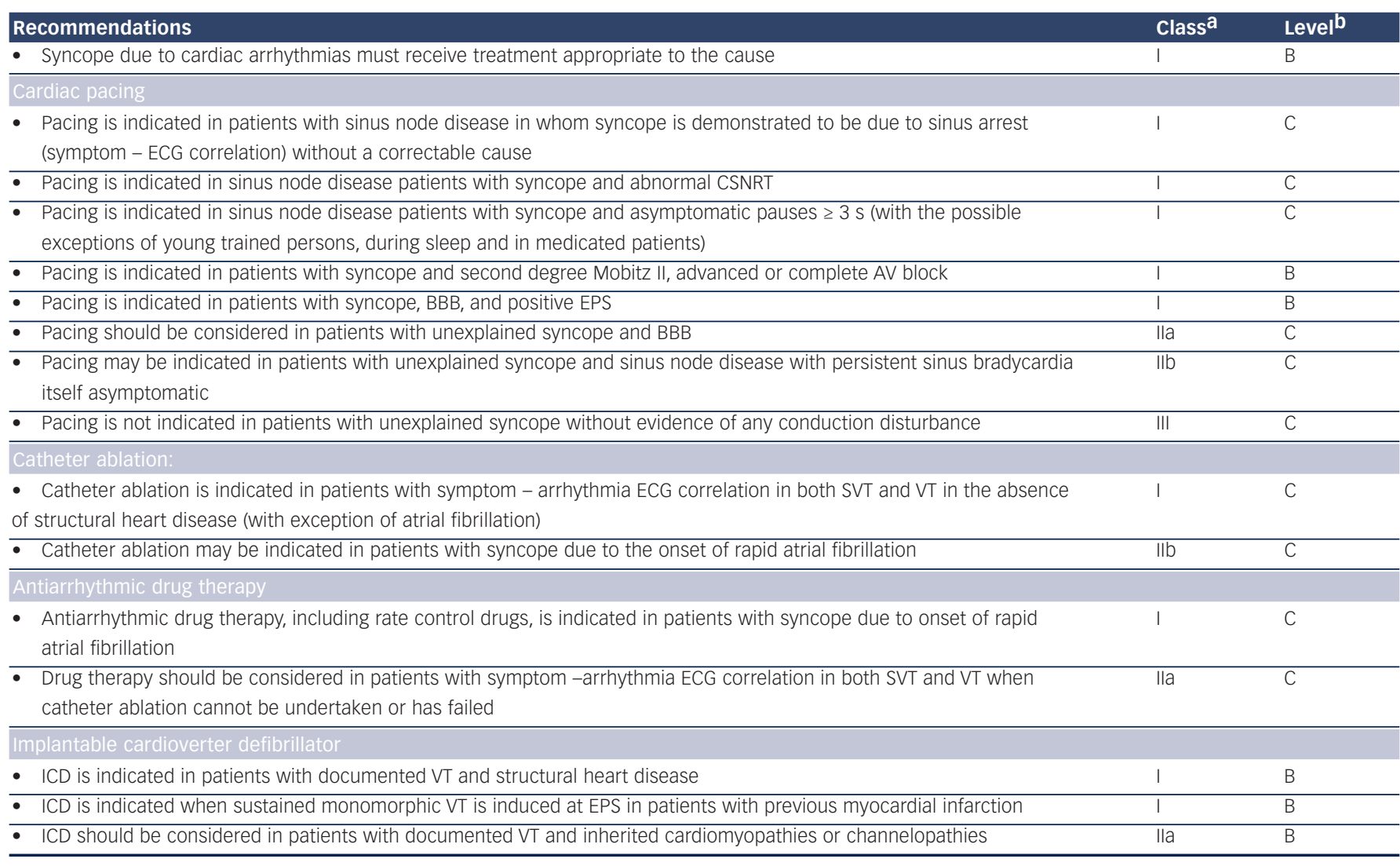

a - Class of recommendation; $b$ - Level of evidence. $A V=$ atrioventricular; $B B B=$ bundle branch block; $C S N R T=$ corrected sinus node recovery time; $E C G=$ electrocardiogram;

EPS = electrophysiological study; ICD = implantable cardioverter defibrillator; SVT = supraventricular tachycardia; VT = ventricular tachycardia. With permission from oxford University Press (UK) (c) European Society of Cardiology (www.escardio.org/guidelines).

is based on confirmation of an inducible arrhythmia or conduction disturbance. ${ }^{101}$ The benefit is dependent on pretest probability based on the presence of organic heart disease or an abnormal ECG. ${ }^{102}$

Electrophysiological study has the advantage of providing both diagnosis and treatment in the same session (i.e. transcatheter ablation). ${ }^{24}$ It is most effective for identification of sinus node dysfunction in the presence of significant sinus bradycardia of $50 \mathrm{bpm}$ or less; prediction of impending high-degree atrioventricular (AV) block in patients with bifascicular block; inducible monomorphic VT (in patients with previous myocardial infarction [MI]) and inducible SVT with hypotension in patients with palpitations. ${ }^{24}$

\section{Management of Cardiac Syncope}

Management of cardiac syncope is dependent on specific cardiac diagnosis as outlined in see Table $6 .{ }^{1}$

\section{Challenges in the Older Patient \\ Frailty}

As people are living longer, frailty and pre-frailty are more commonly encountered in clinical practice. Frailty is a reduction in the ability to respond to stressors and an increased vulnerability to adverse outcomes. ${ }^{103}$ There is no consensus on how best to operationalise or define frailty but two types of definitions have emerged as the most commonly used constructs: the Cumulative Burden Index as proposed where frailty is defined as an accumulation of health conditions and deficits, and the 'Biological Syndrome Model' as proposed by Fried:103 a person is deemed to be frail if they present with three or more of: poor grip strength, slow walking speed, low levels of physical activity, exhaustion and unintentional weight loss. Frailty is a predictor of falls, hospitalisation, disability and death. ${ }^{103}$

\section{Unwitnessed Events in the Older Person}

In the older adult a witness account may not be available for falls or syncopal events in up to $40 \%$ of patients. ${ }^{16}$

\section{Medications, Polypharmacy and Syncope}

Polypharmacy is more common with advancing age. Some of the most frequently prescribed syncope-related medications used in combination are anti-hypertensives, anti-anginals, anti-histamines, anti-psychotics, tricyclic anti-depressants and diuretics. These cause bradycardia, QT interval prolongation, $\mathrm{OH}$ and WVS. Drug interactions can also cause syncope particularly in the older patient with multi-morbidity and polypharmacy. ${ }^{104}$ A temporal association between onset or change of medication and symptoms may be evident although progression of age-related physiological changes may cause syncope even with longstanding established medication use. ${ }^{24}$

TILDA reported an increased risk and frequency of syncope with use of tricyclic anti-depressants. ${ }^{105}$ The side effect most frequently reported is hypotension, but bradycardia and tachycardia have also been reported..$^{106,107}$

\section{Cognition}

Cognitive impairment rises with age: $20 \%$ of people over 80 years have established dementia, ${ }^{108}$ rising to $40 \%$ over 90 years. ${ }^{109}$ Cognitive impairment is characterised by memory problems, attention difficulties and executive dysfunction - hence compliance with cardiac monitoring systems may be compromised. 
Cognitive impairment is particularly high in older patients with $\mathrm{CSH}^{.55}$ Likewise, patients with some subtypes of dementia such as Lewy Body dementia ${ }^{55}$ and Alzheimer's dementia have a higher prevalence of syncope, $\mathrm{OH}$ and $\mathrm{CSH}^{108}$ Establishing a causal relationship between symptoms and arrhythmia or hypotension is particularly difficult in these patients given that the history is not reliable and events are often unwitnessed. $3,6,110$

There is emerging evidence that low BP may cause or exaggerate cognitive dysfunction, ${ }^{111}$ possibly because cerebral hypoperfusion is associated with cerebral damage via small vessel arteriosclerosis and cerebral amyloid angiopathy, as well as exaggerated white matter disease. ${ }^{112}$

\section{Dual Diagnosis}

In the older patient multiple causes of syncope may be present including cardiac (bradyarrhythmia, SVT tachyarrhythmias, ventricular tachyarrhythmias, Iong QT) and reflex syncope or autonomic impairment Table $3 .^{22}$ Attribution of cause in the context of multiple abnormalities is not always possible, and treatment of all possible causes is recommended.

In one series of patients with syncope, mean age 66.5 years \pm 18 years; $23 \%$ had a dual diagnosis. The principal predictors of dual diagnosis were advanced age, treatment with alpha-receptor blockers and benzodiazepines. The most frequent dual diagnoses were $\mathrm{OH}$ and VVS: $2.8 \%$ had a triple diagnosis, and these were the oldest old. ${ }^{28}$

\section{Focal Neurology with Syncope}

Transient ischaemic attacks or stroke and syncope are considered mutually exclusive presentations. However, one recent series reported that $5.7 \%$ of syncope patients experienced focal neurological events at the time of syncope or pre-syncope. Awareness of this phenomenon is important to prevent misdiagnosis of stroke and inappropriate increase of anti-hypertensive medications, which would further exacerbate hypotensive symptoms. ${ }^{113,114}$

\section{Conclusion/Summary}

One of the greatest achievements of public health in the twentieth century has been the almost doubling of life expectancy in the Western world. Healthcare professionals are increasingly treating more old and very old patients. The prevalence of syncope rises with age and is challenging because of atypical presentation, overlap with falls and poor recall of events. Elders are less likely to have a prodrome, may have amnesia for loss of consciousness and unwitnessed events. Cardiac causes and dual pathology are more common and compliance with newer monitoring technologies is inadequate. Consequent morbidity and mortality is higher than in younger patients. A high index of suspicion for cardiovascular causes of falls and dual pathology will increase diagnosis and early targeted intervention.
1. Moya A, Sutton $R$, Ammirati $F$, et al., Guidelines for the diagnosis and management of syncope (version 2009), Eur Heart J, 2009;30(21):2631-71.

2. Kenny RA, Bhangu J, King-Kallimanis BL, Epidemiology of syncope/collapse in younger and older Western patien populations, Prog Cardiovasc Dis, 2013;55(4):357-63.

3. O'Dwyer C, Bennett K, Langan Y, et al., Amnesia for loss of consciousness is common in vasovagal syncope, Europace, 2011;13(7):1040-5.

4. Kenny RA, Syncope in the elderly: diagnosis, evaluation, and treatment, J Cardiovasc Electrophysiol, 2003;14(Suppl. 9):S74-7. treatment, J Cardiovasc Electrophysiol, 2003;14(Suppl. 9):S74-7.
Parry SW, Steen IN, Baptist M, Kenny RA, Amnesia for loss of consciousness in carotid sinus syndrome: implications for consciousness in carotid sinus syndrome: Implications for
presentation with falls, I Am Coll Cardiol, 2005;45(11):1840-3.

6. Shaw FE, Kenny RA, The overlap between syncope and falls in the elderly, Postgrad Med J, 1997;73(864):635-9.

7. Marrison VK, Fletcher A, Parry SW, The older patient with syncope: practicalities and controversies, Int I Cardiol, 2012;155(1):9-13.

8. Kerr SR, Pearce MS, Brayne C, et al., Carotid sinus hypersensitivity in asymptomatic older persons: implications for diagnosis of syncope and falls, Arch Intern Med, 2006:166(5):515-20.

9. Brignole M, Menozzi C, Maggi R, et al., The usage and diagnostic yield of the implantable loop-recorder in detection of the mechanism of syncope and in guiding effective antiarrhythmic therapy in older people, Europace, 2005;7(3):273-9.

10. Ruwald MH, Lock Hansen M, Lamberts M, et al., Unexplained Syncope and Diagnostic Yield of Tests in Syncope According to the ICD-10 Discharge Diagnosis, I Clin Med Res, 2013:5(6):441-50.

11. Linzer M, Pontinen M, Gold DT, et al., Impairment of physical and psychosocial function in recurrent syncope, I Clin Epidemiol, 1991;44(10):1037-43.

12. van Dijk N, Sprangers MA, Colman N, et al., Clinical factors associated with quality of life in patients with transient loss of consciousness, I Cardiovasc Electrophysiol, 2006;17(9):998-1003.

13. Santhouse J, Carrier C, Arya S, et al., A comparison of selfreported quality of life between patients with epilepsy and neurocardiogenic syncope, Epilepsia, 2007;48(5):1019-22.

14. Wieling W, Ganzeboom KS, Krediet CT, et al., [Initial diagnostic strategy in the case of transient losses of consciousness: the importance of the medical historyl, Ned Tijdschr Geneeskd, 2003;147(18):849-54

15. Soteriades ES, Evans JC, Larson MG, et al., Incidence and prognosis of syncope, N Engl J Med, 2002;347(12):878-85.

16. McIntosh S, Da Costa D, Kenny RA, Outcome of an integrated approach to the investigation of dizziness, falls and syncope in elderly patients referred to a 'syncope' clinic, Age Ageing, 1993;22(1):53-8

17. Olde Nordkamp LR, van Dijk N, Ganzeboom KS, et al., Syncope prevalence in the ED compared to general practice and population: a strong selection process, Am J Emerg Med, 2009:27(3):271-9.

18. Del Rosso A, Alboni P, Brignole M, et al., Relation of clinical presentation of syncope to the age of patients, Am I Cardiol, 2005;96(10):1431-5

19. Ungar A, Mussi C, Del Rosso A, et al., Diagnosis and characteristics of syncope in older patients referred to geriatric departments, J Am Geriatr Soc, 2006;54(10):1531-6

20. Go AS, Mozaffarian D, Roger VL, et al., Heart disease and stroke statistics - 2013 update: a report from the American Heart Association, Circulation, 2013;127(1):e6-e245.

21. Parry SW, Tan MP, An approach to the evaluation and management of syncope in adults, BMJ, 2010;340:c880

22. Chen LY, Gersh BJ, Hodge DO, et al., Prevalence and clinical outcomes of patients with multiple potential causes of syncope, Mayo Clin Proc, 2003;78(4):414-20.

23. Romme JJ, van Dijk N, Boer KR, et al., Influence of age and gender on the occurrence and presentation of reflex syncope, Clin Auton Res, 2008;18(3):127-33.

24. Tan MP, Kenny RA, Cardiovascular assessment of falls in older people, Clin Interv Aging, 2006;1(1):57-66.

25. Colman N, Nahm K, Ganzeboom KS, et al., Epidemiology of reflex syncope, Clin Auton Res, 2004;14(Suppl. 1):9-17

26. Overstall P, Drop attacks. In: Syncope in the Older Patients: Causes, Investigations and Conequences of Syncope and Falls, London, UK: Chapman \& Hall Medical, 1996;299-308.

27. Parry SW, Reeve P, Lawson J, et al., The Newcastle protocols 2008: an update on head-up tilt table testing and the management of vasovagal syncope and related disorders, Heart, 2009;95(5):416-20.

28. Rafanelli M, Morrione A, Landi A, et al., Neuroautonomic evaluation of patients with unexplained syncope: incidence of complex neurally mediated diagnoses in the elderly, Clin Interv Aging, 2014;9:333-9.

29. Freeman R, Wieling W, Axelrod FB, et al., Consensus statement on the definition of orthostatic hypotension, neurally mediated syncope and the postural tachycardia syndrome, Clin Auton Res, 2011;21(2):69-72.

30. Duncan GW, Tan MP, Newton JL, et al., Vasovagal syncope in the older person: differences in presentation between olde and younger patients, Age Ageing, 2010;39(4):465-70.

31. Alboni $\mathrm{P}$, Brignole $\mathrm{M}$, Degli Uberti $\mathrm{EC}$, Is vasovagal syncope disease?, Europace, 2007;9(2):83-7.

32. Alboni P, Brignole M, Menozzi C, et al., Clinical spectrum of neurally mediated reflex syncopes. Europace, 2004;6(1):55-62.

33. Graham LA, Kenny RA, Clinical characteristics of patients with vasovagal reactions presenting as unexplained syncope Europace, 2001;3(2):141-6.

34. Tan MP, Parry SW, Vasovagal syncope in the older patient, J Am Coll Cardiol, 2008; 51(6):599-606.

35. Grubb BP, Karas B, Diagnosis and management of neurocardiogenic syncope, Curr Opin Cardiol, 1998;13(1):29-35.

36. Kenny RA, Ingram A, Bayliss J, Sutton R, Head-up tilt: a useful test for investigating unexplained syncope, Lancet, 1986;1(8494):1352-5

37. Kenny RA, O'Shea D, Parry SW, The Newcastle protocols for head-up tilt table testing in the diagnosis of vasovaga syncope, carotid sinus hypersensitivity, and related disorders, Heart, 2000;83(5):564-9.
38. Shaw FE, Bond J, Richardson DA, et al., Multifactorial intervention after a fall in older people with cognitive impairment and dementia presenting to the accident and emergency department: randomised controlled trial, BMJ, 2003;326(7380):73.

39. Parry SW, Gray JC, Newton JL, et al., 'Front-loaded' head-up tilt table testing: validation of a rapid first line nitrateprovoked tilt protocol for the diagnosis of vasovagal syncope, Age Ageing, 2008;37(4):411-5.

40. Bartoletti A, Alboni P, Ammirati $F$, et al. 'The Italian Protocol': a simplified head-up tilt testing potentiated with oral nitroglycerin to assess patients with unexplained syncope. Europace, 2000;2(4):339-42.

41. Brignole M, Menozzi C, Del Rosso A, et al., New classification of haemodynamics of vasovagal syncope: beyond the VASIS classification. Analysis of the pre-syncopal phase of the tilt test without and with nitroglycerin challenge. Vasovaga Syncope International Study, Europace, 2000;2(1):66-76.

42. Parry SW, Matthews I, The implantable loop recorder in older patients with syncope: is sooner better?, Age Ageing, 2010;39(3):284-5

43. Brignole M, Sutton R, Menozzi C, et al., Lack of correlation between the responses to tilt testing and adenosine triphosphate test and the mechanism of spontaneous neurally mediated syncope, Eur Heart J, 2006;27(18):2232-9.

44. Brignole M, Sutton R, Menozzi C, et al., Early application of an implantable loop recorder allows effective specific therapy in patients with recurrent suspected neurally mediated syncope, Eur Heart J, 2006;27(9):1085-92.

45. Brignole $\mathrm{M}$, Donateo $\mathrm{P}$, Tomaino $\mathrm{M}$, et al., Benefit of pacemaker therapy in patients with presumed neurally mediated syncope and documented asystole is greater when tilt test is negative: an analysis from the third International Study on Syncope of Uncertain Etiology (ISSUE-3), Circ Study on Syncope of Uncertain Etiology
Arrhythm Electrophysiol, 2014;7(1):10-6.

46. Brignole M, Menozzi C, Moya A, et al., Pacemake therapy in patients with neurally mediated syncope and documented asystole: Third International Study on Syncope of Uncertain Etiology (ISSUE-3): a randomized trial, circulation, 2012;125(21):2566-71.

47. Parry SW, Matthews IG, Update on the role of pacemaker therapy in vasovagal syncope and carotid sinus syndrome, Prog Cardiovasc Dis, 2013:55(4):434-42.

48. Mathias $\mathrm{CJ}$, Young TM, Water drinking in the management of orthostatic intolerance due to orthostatic hypotension, vasovagal syncope and the postural tachycardia syndrome Eur J Neurol, 2004;11(9):613-9.

49. Tan MP, Newton JL, Chadwick TJ, et al., Home orthostatic training in vasovagal syncope modifies autonomic tone: results of a randomized, placebo-controlled pilot study, Europace, 2010;12(2):240-6.

50. Epstein $A E$, DiMarco JP, Ellenbogen $K A$, et al., ACC/AHA/ HRS 2008 Guidelines for Device-Based Therapy of Cardiac Rhythm Abnormalities: a report of the American College of Cardiology/American Heart Association Task Force on Practice Guidelines (Writing Committee to Revise the ACC/ 
AHA/NASPE 2002 Guideline Update for Implantation of Cardiac Pacemakers and Antiarrhythmia Devices): developed in collaboration with the American Association for Thoracic Surgery and Society of Thoracic Surgeons, Circulation, 2008:117(21): $: 350-408$

51. Sutton $R$, Ungar $A$, Sgobino $P$, et al., Cardiac pacing in patients with neurally mediated syncope and documented asystole: effectiveness analysis from the Third International Study on Syncope of Uncertain Etiology (ISSUE-3) Registry, Europace, 2014;16(4):595-9.

52. Parry SW, Kenny RA, Drop attacks in older adults: systematic assessment has a high diagnostic yield, I Am Geriatr SOC, 2005;53(1):74-8

53. Krediet CT, Parry SW, Jardine DL, et al., The history of diagnosing carotid sinus hypersensitivity: why are the current criteria too sensitive?, Europace, 2011;13(1):14-22.

54. Wieling W, Thijs RD, van Dijk N, et al., Symptoms and signs of syncope: a review of the link between physiology and clinica clues. Brain, 2009;132(Pt 10):2630-42.

55. Kenny RA, Shaw FE, O'Brien JT, et al., Carotid sinus syndrom is common in dementia with Lewy bodies and correlates with deep white matter lesions, I Neurol Neurosurg Psychiatry, 2004;75(7):966-71

56. Ballard C, O'Brien J, Barber B, et al., Neurocardiovascular instability, hypotensive episodes, and MRI lesions in neurodegenerative dementia, Ann N Y Acad Sci, 2000:903:442-5.

57. McIntosh SJ, Lawson J, Kenny RA, Clinical characteristics of vasodepressor, cardioinhibitory, and mixed carotid sinus syndrome in the elderly, Am J Med, 1993;95(2):203-8.

58. Summary of the Updated American Geriatrics Society/British Geriatrics Society clinical practice guideline for prevention of falls in older persons, J Am Geriatr SOC, 2011;59(1):148-57.

59. Brignole M, Menozzi C, Lolli G, et al., Long-term outcome of paced and nonpaced patients with severe carotid sinus syndrome, Am I Cardiol, 1992;69(12):1039-43.

60. Consensus statement on the definition of orthostatic hypotension, pure autonomic failure, and multiple system atrophy. The Consensus committee of the American atrophy. The Consensus Committee of the American
Autonomic Society and the American Academy of Neurology, Autonomic Society and the
Neurology, 1996;46(5):1470.

61. Luukinen H, Koski K, Laippala P, Kivela SL, Prognosis of diastolic and systolic orthostatic hypotension in olde persons, Arch Intern Med, 1999;159(3):273-80

62. Vloet LC, Pel-Little RE, Jansen PA, Jansen RW, High prevalence of postprandial and orthostatic hypotension among geriatric patients admitted to Dutch hospitals, I Gerontol A Biol sci Med Sci, 2005;60(10):1271-7.

63. Mussi C, Ungar A, Salvioli G, et al., Orthostatic hypotension as cause of syncope in patients older than 65 years admitted to emergency departments for transient loss of consciousness, $J$ Gerontol A Biol Sci Med Sci, 2009;64(7):801-6.

64. Frewen J, Finucane C, Savva GM, et al., Orthostatic Hypotension Is Associated With Lower Cognitive Performance in Adults Aged 50 Plus With Supine Hypertension, I Gerontol A Biol Sci Med Sci, 2014;69(7):878-85.

65. Linzer M, Yang EH, Estes NA, 3rd, et al., Diagnosing syncope. Part 1: Value of history, physical examination, and electrocardiography. Clinical Efficacy Assessment Project of the American College of Physicians, Ann Intern Med, 1997:126(12):989-96.

66. LoW PA, Singer W, Management of neurogenic orthostatic hypotension: an update, Lancet neurology, 2008;7(5):451-8.

67. van Lieshout JJ, ten Harkel AD, Wieling W, Physica manoeuvres for combating orthostatic dizziness autonomic failure, Lancet, 1992;339(8798):897-8.

68. van Lieshout JJ, ten Harkel AD, Wieling W, Fludrocortisone and sleeping in the head-up position limit the postural decrease in cardiac output in autonomic failure, Clin Auton Res, 2000:10(1):35-42.

69. Omboni S, Smit AA, van Lieshout JJ, et al., Mechanisms underlying the impairment in orthostatic tolerance after nocturnal recumbency in patients with autonomic failure, Clin Sci (Lond), 2001;101(6):609-18.

70. Podoleanu C, Maggi R, Brignole M, et al., Lower imb and abdominal compression bandages prevent progressive orthostatic hypotension in elderly persons: a andomized single-blind controlled study, I Am Coll Cardiol, 2006;48(7):1425-32.

71. Smit AA, Wieling W, Fujimura J, et al., Use of lower abdomina compression to combat orthostatic hypotension in patients with autonomic dysfunction, Clin Auton Res, 2004:14(3):167-75.

72. Schroeder C, Bush VE, Norcliffe $\perp$, et al., Water drinking acutely improves orthostatic tolerance in healthy subjects, Circulation, 2002;106(22):2806-11.

73. Jankovic J, Gilden JL, Hiner BC, et al., Neurogenic orthostatic hypotension: a double-blind, placebo-controlled study with midodrine, Am J Med, 1993;95(1):38-48

74. Low PA, Gilden JL, Freeman R, et al., Efficacy of midodrine vs placebo in neurogenic orthostatic hypotension. A randomized, double-blind multicenter study. Midodrine Study Group, JAMA, 1997:277(13):1046-51.

75. Wright RA, Kaufmann HC, Perera R, et al., A double-blind, dose-response study of midodrine in neurogenic orthostatic hypotension, Neurology, 1998;51(1):120-4.

76. Naschitz JE, Slobodin G, Elias N, Rosner I, The patient with supine hypertension and orthostatic hypotension: a clinical dilemma, Postgrad Med J, 2006;82(966):246-53.

77. Kearney F, Moore A, Treatment of combined hypertension and orthostatic hypotension in older adults: more questions than answers still remain, Expert Rev Cardiovasc Ther, 2009:7(6):557-60.

78. Romero-Ortuno R, O'Connell MD, Finucane C, et al., Insights into the clinical management of the syndrome of supine hypertension - orthostatic hypotension $(\mathrm{SH}-\mathrm{OH})$ : the Irish Longitudinal Study on Ageing (TILDA), BMC Geriatr, 2013;13:73.

79. Kapoor WN, Karpf M, Wieand S, et al., A prospective evaluation and follow-up of patients with syncope, N Eng / I Med, 1983;309(4):197-204.

80. Alboni P, Brignole M, Menozzi C, et al., Diagnostic value of history in patients with syncope with or without heart disease, J Am Coll Cardiol, 2001;37(7):1921-8.

81. Aronow WS, Ahn C, Kronzon I, Echocardiographic findings associated with atrial fibrillation in 1,699 patients aged $>60$ years, Am J Cardiol, 1995;76(16):1191-2.

82. Krahn AD, Klein GJ, Yee R, Skanes AC, Detection of asymptomatic arrhythmias in unexplained syncope Am Heart J, 2004; 148(2):326-32.

83. Ermis C, Zhu AX, Pham S, et al., Comparison of automatic and patient-activated arrhythmia recordings by implantable loop recorders in the evaluation of syncope, Am I Cardiol, 2003;92(7):815-9.

84. Moya A, Brignole M, Sutton $R$, et al., Reproducibility of electrocardiographic findings in patients with suspected reflex neurally-mediated syncope, Am I Cardiol, 2008;102(11):1518-23.

85. Moya A, Brignole M, Menozzi C, et al., Mechanism of syncope in patients with isolated syncope and in patients with tiltpositive syncope, Circulation, 2001;104(11):1261-7.

86. Solano A, Menozzi C, Maggi R, et al., Incidence, diagnostic yield and safety of the implantable loop-recorder to detect the mechanism of syncope in patients with and without structural heart disease, Eur Heart I. 2004:25(13):1116-9.

87. Pezawas T, Stix G, Kastner J, et al., Implantable loop recorder in unexplained syncope: classification, mechanism, transien loss of consciousness and role of major depressive disorder in patients with and without structural heart disease, Heart, 2008;94(4):e17

88. Croci F, Brignole M, Alboni P, et al., The application of standardized strategy of evaluation in patients with syncope referred to three syncope units, Europace, 2002;4(4):351-5.

89. Frewen J, Finucane $\mathrm{C}$, Cronin $\mathrm{H}$, et al., Factors that influence awareness and treatment of atrial fibrillation in older adults, QJM, 2013;106(5):415-24.

90. RockX MA, Hoch JS, Klein GJ, et al., Is ambulatory monitoring for "community-acquired" syncope economically attractive? A cost-effectiveness analysis of a randomized trial of external loop recorders versus Holter monitoring, Heart, 2005;150(5):1065
91. Sivakumaran $\mathrm{S}$, Krahn AD, Klein GJ, et al., A prospective randomized comparison of loop recorders versus Holter monitors in patients with syncope or presyncope, Am I Med, 2003;115(1):1-5.

92. Balmelli N, Naegeli B, Bertel O, Diagnostic yield of automatic and patient-triggered ambulatory cardiac event recording in the evaluation of patients with palpitations, dizziness, or syncope, Clin Cardiol, 2003;26(4):173-6.

93. Farwell DJ, Freemantle N, Sulke AN, Use of implantable loop recorders in the diagnosis and management of syncope, Eur Heart J, 2004;25(14):1257-63.

94. Krahn AD, Klein GJ, Yee R, et al., Use of an extended monitoring strategy in patients with problematic syncope. Reveal Investigators, Circulation, 1999;99(3):406-10.

95. Armstrong VL, Lawson J, Kamper AM, et al., The use of an implantable loop recorder in the investigation of unexplained syncope in older people, Age Ageing, 2003;32(2):185-8.

96. Benditt $D G$, Ermis $C$, Pham $S$, et al., Implantable diagnostic monitoring devices for evaluation of syncope, and tachy-and brady-arrhythmias, I Interv Card Electrophysiol, 2003;9(2):137-44.

97. Krahn AD, Klein GJ, Yee R, et al., Cost implications of testing strategy in patients with syncope: randomized assessment of syncope trial, J Am Coll Cardiol, 2003;42(3):495-501.

98. Omran H, Fehske W, Rabahieh R, et al., Valvular aortic stenosis: risk of syncope, I Heart Valve Dis, 1996;5(1):31-4.

99. Sarasin FP, Junod AF, Carballo D, et al., Role of echocardiography in the evaluation of syncope: a prospective study, Heart, 2002:88(4):363-7.

100. Senard JM, Chamontin B, Rascol A, Montastruc JL, Ambulatory blood pressure in patients with Parkinson's disease without an with orthostatic hypotension, Clin Auton Res, 1992;2(2):99-104.

101. Lu J, Lu Z, Voss F, Schoels W, Results of invasive electrophysiologic evaluation in 268 patients with unexplained syncope, J Huazhong Univ Sci Technolog Med Sci, 2003;23(3):278-9.

102. Linzer $\mathrm{M}$, Yang EH, Estes NA, 3rd, et al., Diagnosing syncope. Part 2: Unexplained syncope. Clinical Efficacy Assessment Project of the American College of Physicians, Ann Intern Med, 1997;127(1):76-86

103. Fried LP, Tangen CM, Walston J, et al., Frailty in older adults: evidence for a phenotype. J Gerontol A Biol Sci Med SCI 2001; 56(3):M146-56

104. Gaeta TJ, Fiorini M, Ender K, et al., Potential drug-drug interactions in elderly patients presenting with syncope, $J$ Emerg Med, 2002;22(2):159-62.

105. Bhangu JS, King-Kallimanis B, Cunningham C, Kenny RA, The relationship between syncope, depression and antidepressant use in older adults, Age Ageing, 2014;43(4):502-9.

106. Kremastinos DT, Cardiogenic syncope and serotonin reuptake inhibitors, Hellenic J Cardiol, 2008;49(5):375-6.

107. Vieweg WV, Wood MA, Fernandez A, et al., Proarrhythmic risk with antipsychotic and antidepressant drugs: implications in the elderly. Drugs Aging, 2009;26(12):997-1012.

108. Ballard C, Shaw F, McKeith I, Kenny R, High prevalence of neurovascular instability in neurodegenerative dementias, Neurology, 1998;51(6):1760-2.

109. Lobo A, Launer $\sqcup$, Fratiglioni $L$, et al., Prevalence of dementia and major subtypes in Europe: A collaborative study of population-based cohorts. Neurologic Diseases in the Elderly Research Group, Neurology, 2000;54(11):S4-9.

110. Cummings SR, Nevitt MC, Kidd S, Forgetting falls. The limited accuracy of recall of falls in the elderly, I Am Geriatr Soc 1988;36(7):613-6

111. Frewen J, Savva GM, Boyle G, et al., Cognitive performance in orthostatic hypotension: findings from a nationally representative sample, I Am Geriatr Soc, 2014;62(1):117-22.

112. O'Sullivan M, Lythgoe DJ, Pereira AC, et al., Patterns of cerebral blood flow reduction in patients with ischemic leukoaraiosis, Neurology, 2002:59(3):321-6.

113. Roughton M, Campbell JT, Kavanagh SJ, et al., Stroke, Age Ageing, 2013;42(Suppl. 2):ii31-ii2

114. Ryan DJ, Mahon O, Kenny RA, Harbison JA, Focal neurology occurs with syncope and presyncope, Cerebrovasc Dis, 2013;35(Suppl. 3):172. 